\title{
Moda e memória: a biografia de um vestido de noiva de 1984
}

Fashion and memory: the biography of a 1984 wedding dress

MAGRO, Juliane Salete

Instituto Federal de Santa Catarina - IFSC I julianemagro@hotmail.com

MACEDO, Káritha Bernardo de

Instituto Federal de Santa Catarina - IFSC I karitha23@gmail.com

\begin{abstract}
Resumo
No contexto de intensa transformação da moda na sociedade moderna, surpreende a permanência do ritual de casamento e do vestido de noiva branco. Deste modo, o objetivo deste trabalho é analisar um vestido de noiva de 1984, investigando sua trajetória e seus aspectos físicos. Também foi estudada as principais facetas da moda da época e os sentimentos que permaneceram presentes no vestido após trinta e três anos.

\section{Abstract}

In a context of intense transformation of fashion in modern society, the maintenance of the wedding rituals and the white wedding dress is surprising. Thus, the purpose of this paper is to analyze a wedding dress dated from 1984 by investigating its historical path and formal aspects. We also studied the main characteristics of fashion in that era and the feelings that remained in the dress after thirty-three years.
\end{abstract}

Palavras Chave: Vestido de noiva. História. Biografia. Década de 1980

Keywords: Wedding dress. History. Biography. 1980s. 


\section{INTRODUC̣ÃO}

Este artigo visa elaborar a biografia de um vestido de noiva dos anos 1980, usado pela mãe da autora, a senhora Noeli Salete Magro, na cerimônia de seu casamento em 28 de julho de 1984. Neste estudo, foi analisado o contexto desse vestido e a influência que a moda da década causou no momento da sua criação, bem como os aspectos materiais que compõem o vestido e a construção da peça. Considerando que o vestido foi comprado em 1984, a peça ainda trazia características, do final da década anterior. Desse modo, foram analisados vestígios da moda da década de 1970 e do início de 1980 com foco no traje escolhido, observando as técnicas utilizadas na sua produção, os traços da modelagem, o tipo de tecido, de costura, os aviamentos e a cor.

Roupas são objetos que tem uma circulação social, portanto "sua longevidade, geralmente maior que a humana, as permite transitar por diversos espaços e tempos" (ANDRADE, 2008, p. 1). Assim, analisar uma roupa e escrever a sua biografia, pode ser uma forma de apresentar o estilo de vida de uma determinada classe ou cultura, permeando o contexto de moda que a cercava. O vestido de noiva da senhora Noeli Salete Magro, é uma forma material de representar uma faceta dos acontecimentos que a marcaram o imaginário social no universo estético nesta década. A roupa, além de patrimônio material, pode ser tratada como um patrimônio cultural, visto que traz evidências da vida e dos costumes das pessoas.

A roupa, além de patrimônio material, pode ser tratada como um patrimônio cultural, visto que traz evidências da vida e dos costumes das pessoas. Partindo desse princípio pode se estudar o tempo histórico, condições econômicas, culturais, geográficas, pensamentos, organização social e representações simbólicas de uma sociedade em um determinado momento. Assim, como afirma Lipovetsky (1983, p. 85), podemos considerar a moda um elemento fundamental para a compreensão das sociedades modernas, pois ela está intimamente ligada aos fatos políticos, econômicos e sociais da história mundial, repercutindo nos modos de vestir. Este estudo se faz necessário, pois o objetivo é fornecer informações novas em um universo pouco explorado. Acredita-se que as evidências encontradas ao final desta pesquisa, confrontadas com o estudo bibliográfico, podem fornecer dados relevantes sobre as roupas de rituais, dentre elas, os vestidos de noivas, a cultura e o modo de vida dos antepassados, residentes no Brasil na década de 1980.

\section{MATERIAIS E MÉTODOS}

Essa pesquisa se caracteriza como uma pesquisa básica, pois tem como objetivo preencher uma lacuna de conhecimento sem aplicação prática imediata. Além disso, fundamentou-se o estudo através de pesquisas 
bibliográficas, análise documental e de uma entrevista semiestruturada com a senhora Noeli Salete Magro, dona do vestido de noiva.

A pesquisa bibliográfica focou-se em textos de história da moda, materiais têxteis, costura aplicada e modelagem. A entrevista realizada pela autora, sintetizou perguntas objetivas sobre a peça, tais como: quais os motivos que a levaram a adquirir a peça, o motivo da escolha da peça, onde foi feita/ comprada, a quem pertenceu, quantos anos a peça tem ou aparenta ter e em quais ocasiões foi usada.

A pesquisa documental tomou como objetos a própria roupa e fotos antigas da mesma. Nesse processo, foi realizada uma detalhada análise da peça, buscando-se fundamentar teoricamente o que era percebido visualmente. Para se conseguir visualizar os detalhes já estudados e confirmados, foi realizado um desenho técnico da peça contendo suas medidas.

A pesquisa se configura como qualitativa, na medida em que visa uma análise mais profunda em relação ao fenômeno estudado, pois faz uma conexão do elemento estudado e o mundo em que vive sem pautar-se por números ou dados quantitativos. A pesquisa volta-se a observar e analisar seus dados indutivamente.

\section{UMA NOIVA EM SEU TEMPO}

A dona do vestido de noiva analisado neste trabalho, a senhora Noeli Salete Magro, veio de uma família tradicional italiana, seus bisavós migraram da Itália em busca de uma vida melhor no Sul no Brasil, para a cidade de Concórdia, Santa Catarina, em meados de 1800. Noeli é a filha mais velha de quatro irmãos, teve uma infância comum e cresceu no campo onde ajudava seus pais que viviam da agricultura. Sua família era muito religiosa, frequentavam juntos os cultos católicos todos os domingos de manhã, e foi nesse meio, em uma festa do padroeiro da igreja que a Noeli conheceu o Neudi, seu atual marido. Neudi Magro também é o filho mais velho de uma tradicional e católica família Italiana. Após se conhecerem e se apresentarem às famílias, o casal namorou cerca de quatro 4 anos e então se casaram.

Após marcada a data para o casamento, começou-se a preparação para a festa que foi toda organizada pela família do noivo juntamente com a Noeli. O casamento aconteceu no dia 28 de julho de 1984, na capela da comunidade de Linha Caravaggio, em concórdia, onde reside até hoje a família do noivo. Foi uma cerimônia simples, porém, com muitos convidados, os quais foram recepcionados com uma festa no quintal da casa onde residiam os pais e irmãos do noivo. Tem-se muitos registros desta data, pois as famílias fizeram questão de guardar em fotografias todos os detalhes deste dia tão importante. 
Em uma entrevista com Noeli, ela contou que comprou o seu vestido na Loja Arendth, fundada em 1977 e localizada no centro da cidade de Concórdia até os dias atuais. Na loja encontram-se produtos de cama, mesa e banho, decoração e vestuário feminino. Não era uma loja especializada em vestidos de noiva, mas era uma das poucas situadas na cidade, por consequência, os valores das peças eram maiores que os do mercado em geral. Foi sua sogra, a senhora Odevina Magro, quem a acompanhou na compra do vestido de noiva.

Figura 1 - Casamento de Noeli e Neudi Magro em 28 de julho de 1984.

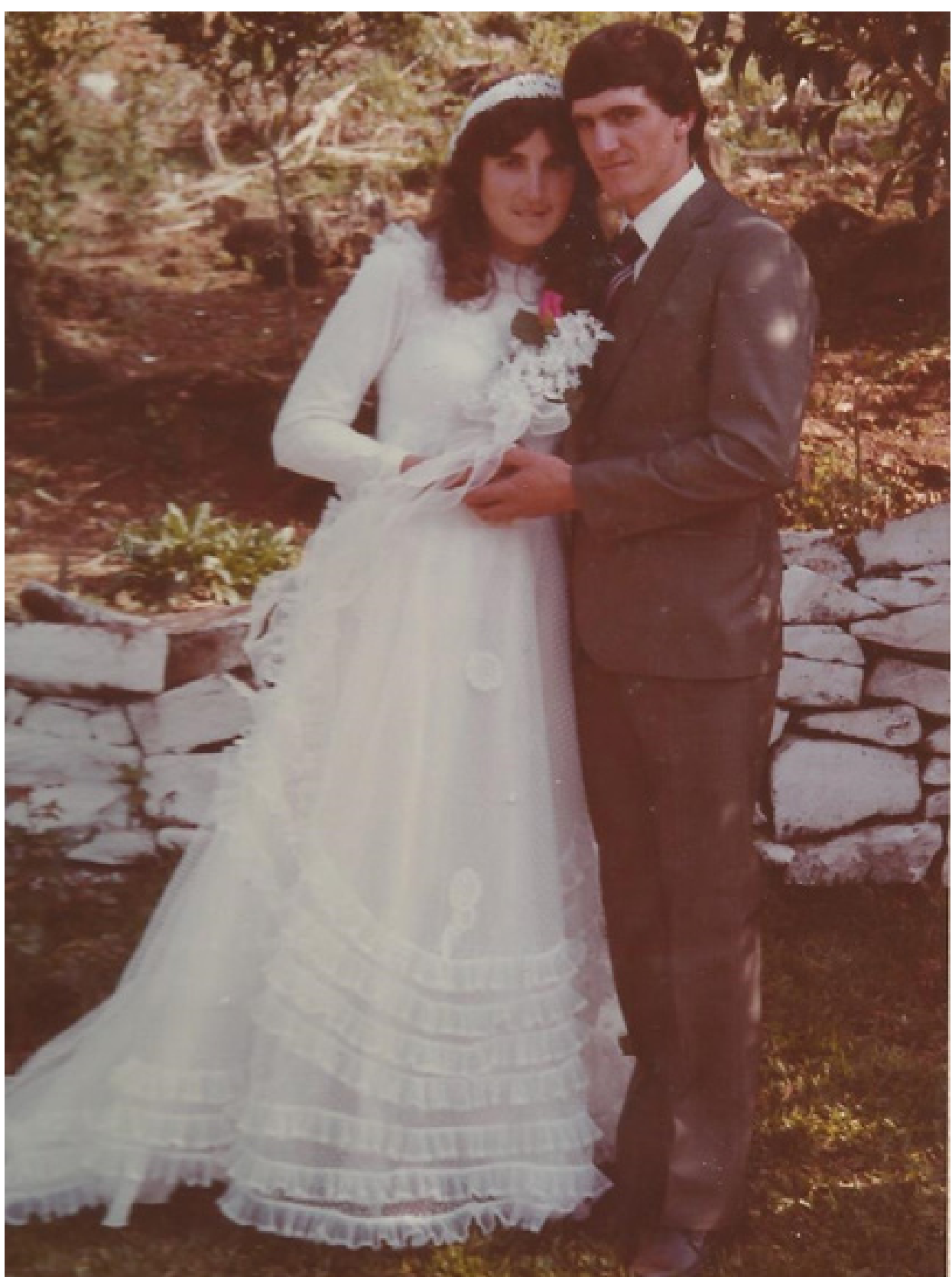

Fonte: Arquivo pessoal de Noeli Magro (1984).

Após provar muitos modelos diferentes de vestidos e escolher um, elas decidiram juntas que a noiva teria de usar uma blusa "segunda pele" por baixo, pois a renda deixava muito do corpo de Noeli à mostra, o que a senhora Odevina julgava desrespeitoso à igreja. Ainda não satisfeitas, elas adaptaram uma saia

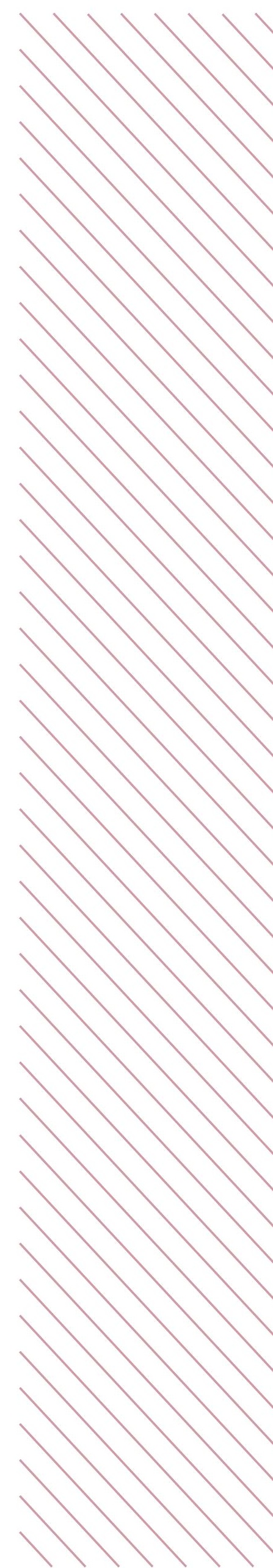


justa na parte inferior da peça, que funcionou como uma anágua. Foi a família do noivo quem pagou todas as despesas do casamento, inclusive, o vestido da noiva, demonstrado na fotografia de Noeli Magro (figura 1 e figura 2).

Figura 2 - Vestido de noiva de 1984, frente e costas.

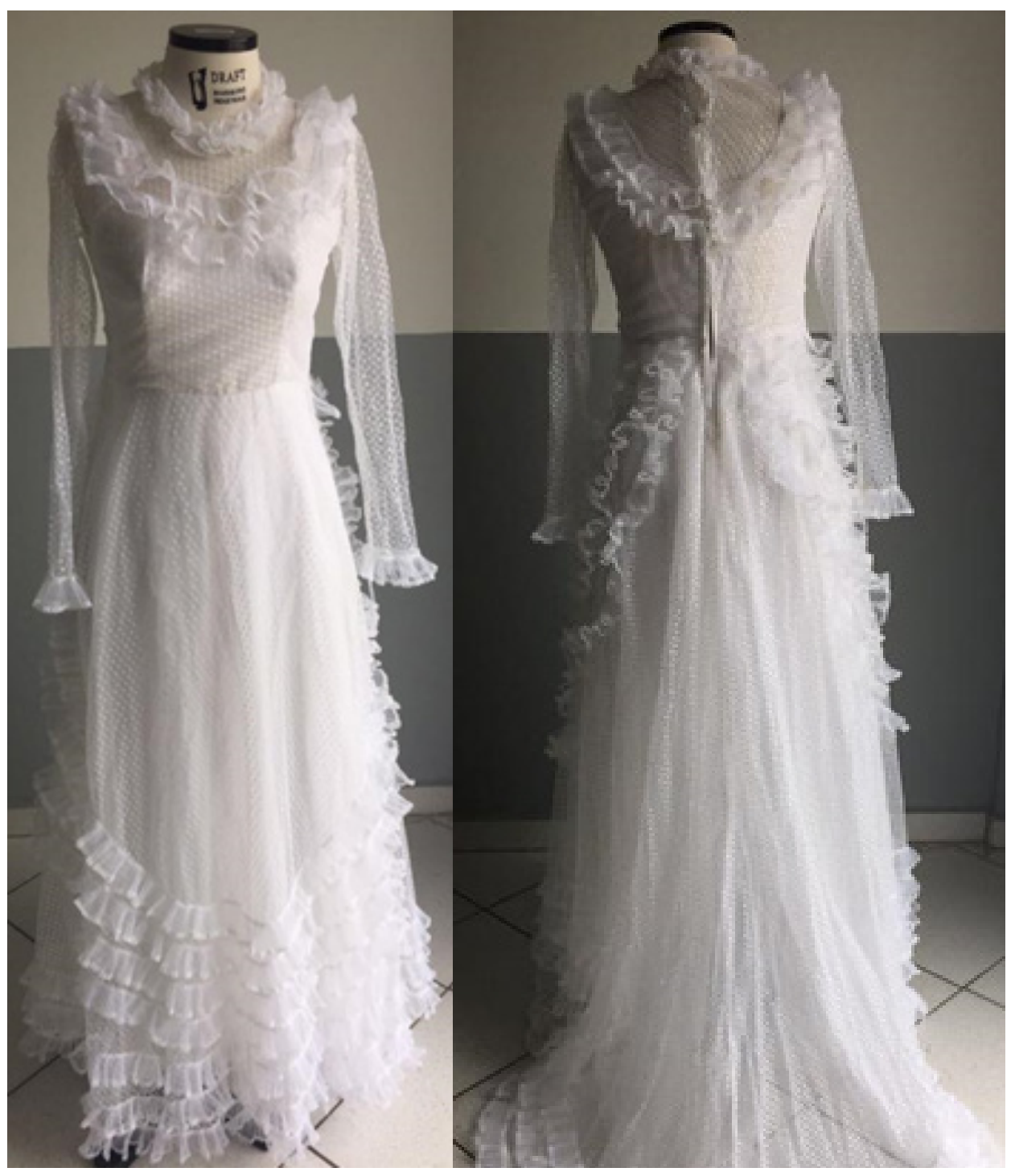

Fonte: Arquivo pessoal de Noeli Magro (1984).

A partir desse ponto, sentiu-se a necessidade de estudar a história da moda a fim de contextualizar o traje escolhido (utilizado em 1984) com o período no qual ele está inserido. A transição da década de 1970 para a década de 1980 foi repleta de acontecimentos históricos, os quais contribuíram para grandes mudanças na sociedade. Um deles foi a luta das mulheres pela igualdade profissional, elas queriam as mesmas oportunidades de empregos de liderança nas mais diversas carreiras, outro ponto de destaque foi a volta à natureza na busca de uma vida mais saudável (MACKENZIE, 2010, p. 114).

No entanto, a moda se diversificou muito a partir dos anos 1970, sendo influenciada por uma série de novos estilos que surgiram ligados a movimentos culturais. Os anos 1970 ficaram conhecidos como "a década 
que o estilo esqueceu", pois foi a década do pluralismo e do vale-tudo na moda (MACKENZIE, 2010, p. 114). Entretanto, esse movimento só viria a se intensificar, pois nos anos 1990 surgiu a expressão "mercado de estilos", porque surgiram tantas opções dentro da moda que as pessoas se sentiam em um supermercado (PALOMINO, 2010, p. 20). Dois grandes movimentos que se destacam nessa época são os punks e hippies, pois deles se desdobraram uma série de outras formas de expressão geralmente ligadas à cultura jovem.

O punk explodiu em meados de 1975, manifestando uma postura anticonformista e inovadora, principalmente por meio do vestuário e da música (MACKENZIE, 2010, p. 106). Os punks eram descritos como jovens rebeldes, cujo propósito se resumia em "chocar a sociedade", eram uma subcultura eclética que se baseara em muitas fontes para evoluir e definir sua estética. (MACKENZIE, 2010, p. 106). O movimento hippie nasceu no final dos anos 1960 e início de 1970 e estava disposto a oferecer uma visão de mundo diferente diante da sociedade capitalista. Traziam ideias e questionamentos ligados ao desapego material e a busca de uma vida mais saudável. Muitos sobreviviam vendendo seu artesanato feito de sementes e matérias-primas naturais (CIDREIRA, 2005, p. 40).

O Romantismo vinha na alçada do movimento hippie, nesse estilo predominavam estampas florais, acabamentos de renda, chapéus de palha e uma série de acessórios com ares românticos sobre o volume de muitos tecidos, especialmente nas saias. Esse tipo de tecido ganhou destaque e tornou-se alvo de preocupações dentre os principais fabricantes têxteis da época, que lançaram um gênero de tecido com caimento suave, muito apropriado para a criação dos desejados trajes folgados e agradáveis de usar (NERY, 2007, p. 55). Laura Ashley ficou conhecida por popularizar na moda o estilo camponês e se tornou um ícone do romantismo. A estilista criou esse novo conceito no momento em que teve a grande ideia de fazer tecidos estampados, quando estava à procura de remendos para fazer pequenas peças. Seu look era composto por saias rodadas com estampas de flores, blusinhas bufantes com bordados, babados e rendas floridas. Características essas, presentes no vestido de noiva estudado neste trabalho.

No contexto histórico da moda, a década de 1970 teve grande influência do movimento hippie e do romantismo, com roupas largas e mangas "boca de sino". Também se nota uma grande diversidade de cores, texturas, formas e trabalhos artesanais. Pode-se apontar ainda os pequenos vestígios que a década de 1970 deixou de herança para o começo da década seguinte, como as calças boca-de-sino, as batas florais, os cabelos longos para ambos os sexos e os acessórios artesanais (NERY, 2007, p. 55), e que podem ser vistos no álbum de casamento de Noeli. Ao pesquisar a moda que sobressaía nos anos 1980, percebeu-se que as mulheres usavam muito cintura e cós altos, ombreiras, pregas e drapeados que eram usados tanto de dia quanto à noite, e várias peças tinham o objetivo de valorizar a cintura feminina (MACKENZIE, 2010, p. 49). 
Este artigo não se detém a descrever tanto os estilos que predominaram na década de 1980, pois após o estudo da história da moda desse período, notou-se que o vestido de casamento de Noeli identificava-se melhor com as referências do romantismo. Portanto, após compreender os principais estilos vigentes no período do casamento, questiona-se agora qual a história dos vestidos de noiva, que apesar de estarem ligados ao contexto de moda do momento, ainda seguem as regras próprias da tradição.

\section{BREVE HISTÓRIA DOS VESTIDOS DE NOIVA}

O vestido branco de noiva, faz parte de um ritual que se tornou uma tradição e que se preserva por gerações. Quando a rainha Vitória da Inglaterra casou com seu primo, o príncipe Albert, em 1840 ela lançou o vestido de noiva branco como símbolo de status, pois o tecido branco era uma cor cara e de difícil manutenção em 1840 (MACKENZIE, 2010, p. 49). Além da rainha Vitória ter persuadido a cor branca dos vestidos de casamento, atualmente é possível perceber também a influência da silhueta da Era Vitoriana sobre os vestidos de noiva. A Era Vitoriana foi marcada pelo período de reinado da Rainha Vitória (1837 - 1901). Sua influência pode ser notada quando se folheia álbuns de casamento antigos de familiares, quando se abre revistas contemporâneas e do passado, ou mesmo em uma simples busca na internet por vestidos de casamento. Nesse período, os vestidos tinham cintura mais baixa, próxima ao quadril, era marcada e ajustada com o auxílio de espartilhos apertados, as mangas eram longas e desciam até o pulso. A saia passou a ser em formato redondo, volumoso e integrada a muitas anáguas sobrepostas (BLACKMAN, 2012, p. 4). Na Era Vitoriana as mulheres tinham de ser consideradas recatas e todo esse traje as impossibilitava de realizar certos movimentos. Usar espartilhos, era considerado uma necessidade, e já era vestido em crianças a partir dos três anos de idade (COSGRAVE, 2012, p. 45).

A partir de então o vestido de noiva passou a ser um dos principais símbolos do casamento, surgiu com o objetivo de apresentar à comunidade as posses da família da noiva (SCHNEID, 2014, p. 3). Ainda nos dias atuais, "muito provavelmente o vestido de noiva será a roupa mais cara que a mulher vestirá na vida, e, acredita-se que será usado apenas uma vez" (WORSLEY, 2010, p. 12). Do ponto de vista católico, entende-se que o vestido de noiva busca uma aproximação com a Virgem Maria, mãe de Jesus Cristo e Santa do culto cristão. Assim, torna-se claro que o objetivo maior é fortalecer o que era entendido como puro e também o cuidado com a virgindade, um princípio a ser seguido pelas mulheres, "moças de família" (ANDRADE, 2013, p. 74). A cor branca na indumentária da noiva no Brasil estava ligada a virgindade e inocência. Segundo Schneid (2014, p. 3), "as roupas nesse momento cumpriam papéis de conexão entre o corpo e a alma, entre o mundo moral e o mundo físico" (SCHNEID, 2014, p. 3). 
A realeza inglesa foi uma difusora desse modelo. Em 1923, o casamento da Rainha Elizabeth repercutiu no mundo inteiro. Lady Elisabeth casou-se com o duque de York usando um simples vestido de chiffon moiré na cor marfim (BLACKMAN, 2012, p. 28). No início do século XX, o vestido de noiva era um privilégio apenas para os ricos, pois até os anos 1930 as noivas de classes mais baixas casavam com seu melhor vestido ou também chamadas "roupas domingueiras" (SCHNEID, 2014, p. 3). Todo o glamour dos anos 1930 deu lugar à simplicidade durante a Segunda Guerra Mundial.

As noivas da década de 1940 procuravam modelos mais simples, pois ostentar trajes luxuosos era visto como antipatriótico devido à carestia causada pela guerra e o alto custo por conta dos impostos do período. Após a Segunda Guerra Mundial, o surgimento do New Look incentiva o luxo, e traz de volta o uso dos espartilhos e da figura feminina apreciada no século XIX. Essa imagem tem ecos nos trajes de casamento, que ganham saias amplas, cinturas afinadas por corsets e o ar romântico vitoriano (século XIX). Com o fim da escassez dos cosméticos do pós-guerra, a beleza novamente se tornaria um tema de grande importância. Em 1950 o clima era de sofisticação, as grandes influências para esses acontecimentos foram as divas de Hollywood que ficaram conhecidas como ingênuas chiques, tais como Grace Kelly e Audrey Hepburn (GARCIA, 2016). Nos anos 1960, Jackie Kennedy com seu estilo sofisticado e inteligente influenciou a maneira de vestir das mulheres de todo mundo e inspirou algumas alterações nos vestidos de noivas, como inserção de golas e encurtamento das mangas (SCHNEID, 2014, p. 3).

Em 1970 os vestidos de noiva foram influenciados pela moda hippie, eram leves e soltos, demarcando a cintura com faixa. As noivas dos anos 1970 seguiam os traços do movimento do Romantismo, adornadas de muita renda, babados, plissados, tules e muitos aviamentos. Os vestidos brancos possuíam transparência, geralmente, no decote e nas mangas, que logo era coberta por outro tecido mais encorpado na parte inferior da peça, uma espécie de forro. As saias eram compostas por inúmeras camadas de tecidos sobrepostas umas às outras (SCHNEID, 2014, p. 4). Essas camadas além de ocultar qualquer parte do corpo feminino que pudesse estar à mostra, davam continuidade à tradição colocada no tempo da rainha Vitória e tinham o objetivo de mostrar a comunidade as posses da família da noiva através dos incontáveis metros gastos de tecido (SCHNEID, 2014, p. 4).

Dentre as classes altas o branco permaneceu até o final do século. Foi a partir dos anos 1980 que começaram a surgir vestidos de noivas em outras cores. Acredita-se que nesse período a moda já "permitia" essa flexibilidade, principalmente por conta dos movimentos de emancipação e empoderamento feminino que insurgiram nas décadas anteriores. Todavia, quando o vestido de noiva não era branco por escolha pessoal ou por gravidez antes do casamento, geralmente utilizavam-se outras duas cores: o rosa bebê ou o azul celeste. Como chama-se na linguagem da moda, tons pastéis (SCHNEID, 2014, p. 5). 
Foi nos anos 1980 que as saias passaram a ter menos camadas, porém, eram contempladas com uma anágua que aumentava até três vezes o tamanho da saia do vestido. Os decotes, que antes eram até próximos ao pescoço passaram a mostrar mais o busto (SCHNEID, 2014, p. 4). Além disso, foram adicionadas aos vestidos ombreiras que exaltavam todo o colo feminino, como pode ser observado no painel semântico de vestidos de casamento do período, figura 3. O painel semântico apresentado na figura 3 representa trajes e vestidos de casamento utilizados em um período próximo ao casamento de Noeli, e que possuem uma silhueta ou aspectos que remetem ao vestido analisado neste artigo.

Figura 3 - Painel Semântico: Vestidos de noiva 1970 e 1980.

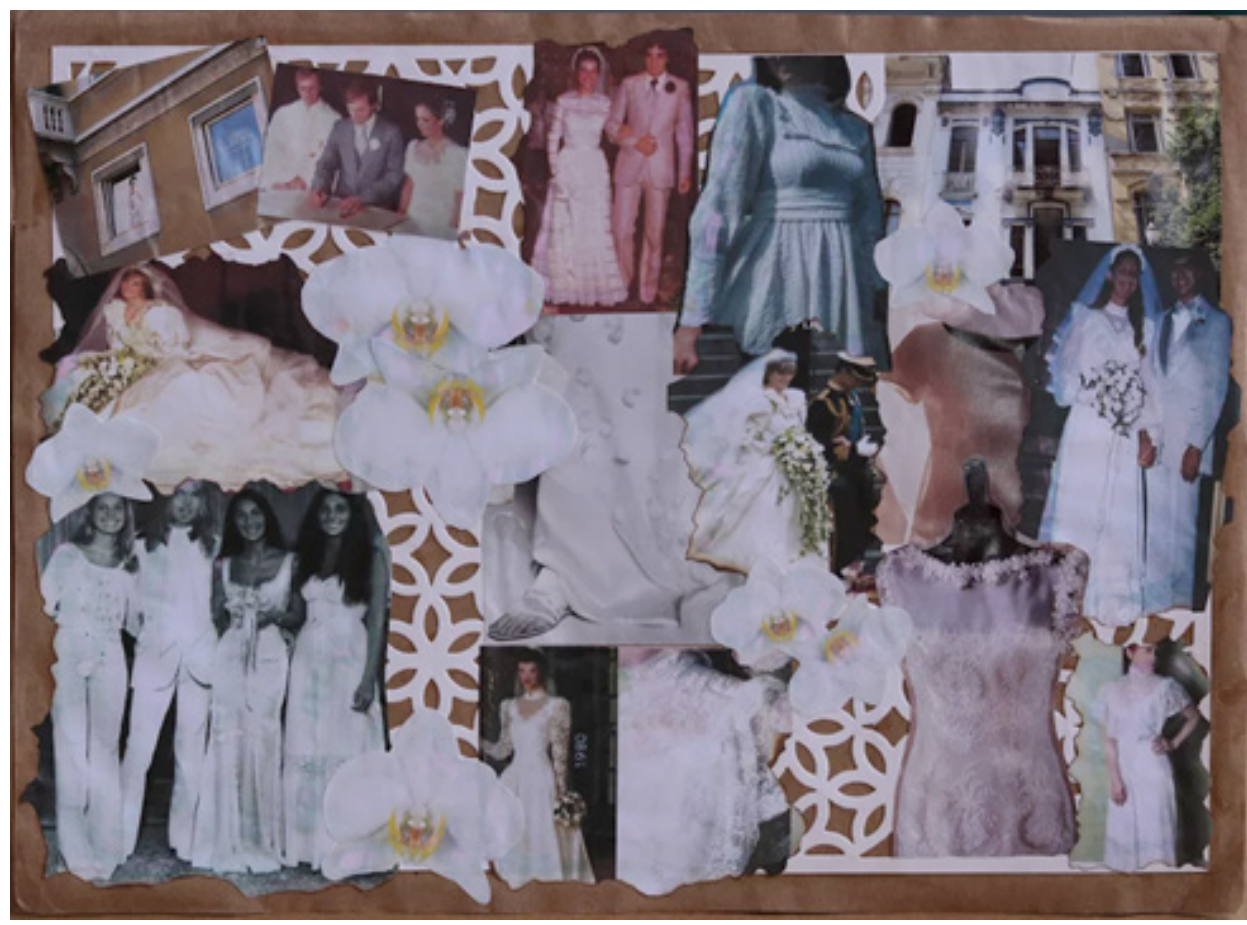

Fonte: Produzido pela autora, 2017.

Após essa breve pesquisa sobre vestidos de noiva, notou-se que o vestido estudado neste artigo apesar de ser dos anos 1980, apresenta apenas características dos anos 1970. Isso se dá pelo fato da moda chegar em ritmo mais lento no Brasil, e principalmente no interior do estado após ser lançada pelas influências da mídia ou até mesmo pelos grandes polos de moda do mundo. Desta forma, o vestido aqui mencionado apresenta peculiaridades dos anos 1970, como cintura alta e marcada por fitas largas, gola alta, geralmente de renda contendo transparências, mangas longas afuniladas no pulso e ainda um grande volume de tecido presente nas saias, conforme a figura 3.

\section{DESCRIC̣ÃO FÍSICA E ANÁLISE MATERIAL DA ROUPA}

A análise física da roupa foi feita por meio de observações na peça selecionada, tanto na parte do lado direito quanto na parte do avesso, pois 
procurava-se compreender todos os detalhes, tais como: forma, tamanho, cor, textura, cheiro e marcas de uso. Para realizar um estudo mais aprofundado da modelagem e dos aspectos físicos do vestido, realizou-se um desenho técnico do vestido de casamento analisado, contemplando suas medidas, apresentado na figura 4. Esta ação também possibilitaria uma reprodução do vestido. Durante a análise foram tiradas as seguintes conclusões.

Figura 4 Desenho técnico vestido de noiva anos 1980, frente e costas.
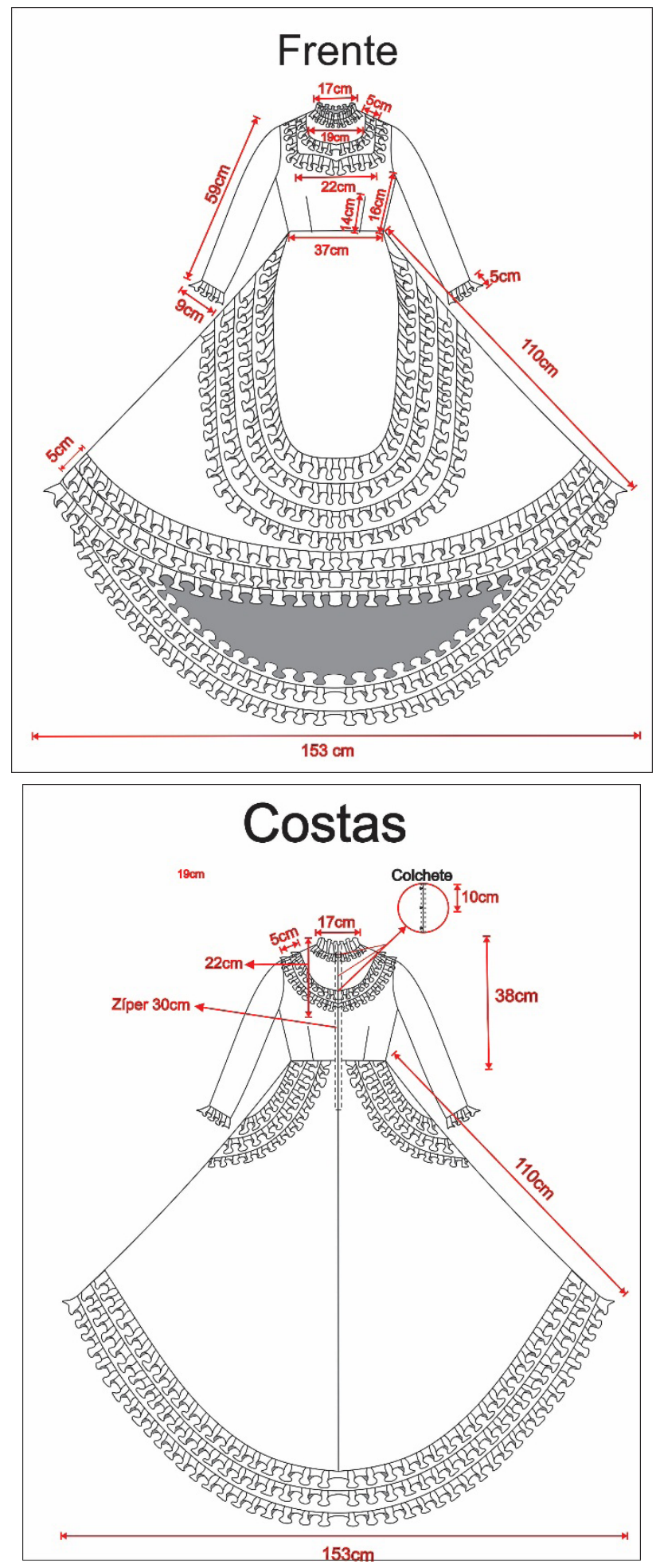

Fonte: Produzido pela autora, 2016. 
A parte inferior do vestido é composta por três camadas de saias, cada uma delas cortada em um tecido diferente, porém, todos em tons off white. A primeira camada de saia é a mais longa, pois possui uma cauda na parte de trás. Foi cortada considerando o lado mais liso e brilhoso como direito e o lado mais áspero e fosco como o avesso. O tecido foi identificado por apresentar características do que conhecemos hoje por faillete, porém, com um toque bem mais espesso. A segunda saia foi cortada em um tecido sintético transparente não identificado, contudo, o mesmo apresenta características de nylon e assemelha-se ao voil. A última camada do vestido vem sobrepondo todas as outras em uma renda de poliéster com detalhes geométricos, os quais lembram a estrutura de uma rede. Todas essas saias têm formato de três quartos de godê, o que proporciona um grande volume de tecidos.

Ainda assim, afim de ocultar qualquer tipo de transparência existente, Noeli juntamente com sua sogra Odevina adaptaram uma quarta saia abaixo de todas as mencionadas, que tinha o objetivo de funcionar como uma anágua, além de resguardar a modéstia da noiva. Essa saia, diferente das demais, tinha comprimento pouco abaixo do joelho, justa ao corpo, confeccionada em tecido de algodão cru. Observando a parte interna do vestido, nota-se perfeitamente a adição desta última saia com costura manual e sem acabamentos.

A modelagem de todas as camadas de saias tem medidas semelhante ao que conhecemos nos dias atuais por tamanho 40. Elas têm cintura alta e comprimento longo, ou seja, que cobre os pés (a lateral da saia, desde a junção com a parte superior até o fim da barra, mede $110 \mathrm{~cm}$ ). As saias não possuem costura lateral, apenas uma única costura na parte de trás da peça, que segue na direção do zíper. A saia é adornada com quatro fileiras de babados de renda em toda circunferência da barra e também na parte da frente no estilo avental que seguem até a parte de trás encontrando-se com o zíper. Esses babados são plissados e o acabamento é feito com uma fita de renda de algodão. $\mathrm{O}$ detalhamento da peça pode ser observado na figura 4.

A parte superior do vestido é formada também pelo tecido semelhante ao failette e pela mesma renda de algodão. Os dois tecidos juntos formam um decote quadrado que termina com um bico na região do busto. Apresentando ainda duas camadas de babado. Em seguida tem-se outro decote confeccionado apenas com a renda que segue formando uma gola alta até o pescoço. Sendo finalizado com mais duas camadas de babado em toda sua circunferência. O vestido por completo apresenta algumas marcas de uso, como manchas amareladas, costuras abertas e pequenos rasgos no forro. O cheiro de roupa guardada também está presente, afinal, permaneceu mais de trinta e dois anos em uma caixa.

Para confeccionar o vestido foram utilizados quatro tipos de tecido que não foram identificados concretamente. $O$ primeiro deles muito semelhante ao que conhecemos como failette, pois designa tecido leve, fino e brilhante 
confeccionado com urdidura de seda e trama de algodão ou lã produzindo o efeito canelado e bastante sintético. Sua composição possui poliéster e é geralmente indicado para forro. O segundo tecido é transparente e sintético com características de nylon bastante semelhante ao voil. O terceiro tecido se trata de uma delicada renda com desenhos geométricos que lembram a estrutura de uma rede. Sua composição possui poliamida, algodão e elastano, geralmente utilizado para confecção de cortinas, roupas de cama e toalhas de mesa. E por fim, o quarto tecido apresenta as propriedades do algodão cru. Foi utilizado para fazer a anágua, que foi adicionada após a compra. A costura foi feita manualmente com um alinhavo simples e sem acabamento.

Analisando o avesso do vestido percebeu-se que não existe uma certa regularidade nos acabamentos. O acabamento da primeira e da segunda camada de saia foi feio em uma máquina Overlock simples, assim como a cava e a junção das partes na cintura. Já a terceira camada da saia, confeccionada em renda, não apresenta acabamento externo, apenas um viés simples no decote e no punho interno. As demais costuras do vestido foram feitas em máquina retal manual. $\mathrm{O}$ vestido também possui um zíper de metal com vista. Atualmente esse zíper encontra-se enferrujado devido a oxidação do metal em contato com as partículas de água presente no ar. Essa oxidação ocasionou algumas manchas douradas na parte de trás do vestido. O mesmo acontece com os três colchetes que unem as duas partes das costas até a gola, conforme desenho técnico a seguir.

\section{CONSIDERAC̣ÕES FINAIS}

Neste trabalho foi estudada a transição da moda nos anos 1970 para 1980, a fim de obter-se informações para contextualizar o traje analisado (usado em 1984) com o período no qual está inserido. De modo geral, os anos de 1970 sofreram grande influência do movimento hippie e do romantismo. Além disso, nesse período percebe-se uma intensificação da luta das mulheres por mais direitos e nota-se sua apropriação de formas do vestuário masculino. Já os anos 1980 ficaram marcados pela competição entre os homens e as mulheres em que as últimas estavam à procura de igualdade no mercado de trabalho. Portanto vestiam-se com peças as quais acreditavam não valorizar a feminilidade a fim de ficarem mais parecidas com os homens, que dominavam a política e o mundo dos negócios até então.

Ao fim da pesquisa notou-se que o vestido de noiva estudado neste artigo apresenta principalmente características percebidas dentro da pluralidade que foi o final da década anterior, 1970, não evidenciando ainda os grandes marcos da década de 1980. Isso pode ter acontecido pelo fato da moda chegar em ritmo mais lento no Brasil, e especialmente no interior do estado, após ser lançada pelas influências da mídia ou até mesmo pelos grandes polos de moda do mundo. Tratando-se da década de 1970, destaca-se a influência sobre o vestido 
de casamento analisado do movimento do romantismo e o movimento hippie, sobretudo, de características como a presença de florais, acabamentos de renda, saias rodadas e amplas, e as texturas. Esses detalhes podem ser observados no vestido de noiva estudado neste trabalho, mas além disso, percebe-se uma continuidade desses preceitos na moda de casamento contemporânea.

Sob essa perspectiva, a análise do vestido traz dados que poderiam servir como base para o desenvolvimento de uma releitura ou do desenvolvimento de uma coleção de moda contemporânea em outro momento. Dessa forma, esse estudo poderia desabrochar possibilidades de aplicação no campo da moda tanto esteticamente, quanto em relação aos conceitos que traz consigo.

Logo, essa pesquisa foi significativa pois foi confrontada com o estudo bibliográfico, obteve dados relevantes sobre os vestidos de noivas, sobre a cultura, religiosidade, a história de uma família e alguns hábitos e costumes locais ligados ao casamento, na região de Chapecó no início da década de 1980. 


\section{REFERÊNCIAS}

ANDRADE, Maria Celeste de Moura. O século XIX: o mundo burguês/o casamento/a nova mulher. Evidência, Araxá, v. 8, ed. 9, p. 63-80, 2013.

ANDRADE, Rita Morais. Boué Soeurs RG 7091: a biografia cultural de um vestido. 2008. Tese (Doutorado em História) - Pontifícia Universidade Católica de São Paulo, São Paulo, 2008.

BLACKMAN, Cally. 100 anos de moda. Tradução de Mario Bresighello. São Paulo: Publifolha, 2012.

CIDREIRA, Pitombo Renata. A moda nos anos 60/70 (comportamento, aparência e estilo). Revista do Centro de Artes, Humanidades e Letras, Salvador, v. 2, n. 1, p. 35-44, 2005.

COSGRAVE, Bronwyn. História da indumentária e da moda: da antiguidade aos dias atuais. São Paulo: GG Moda, 2012.

GARCIA, Cláudia. Anos 50: a época da feminilidade. Folha de São Paulo. Almanaque, Banco de Dados Folha, São Paulo. Especial Moda. Disponível em: <http://almanaque.folha.uol.com.br/anos50.htm>. Acesso em: 11 jan. 2016.

LIPOVETSKY, Gilles. O império do efêmero: a moda e seu destino nas sociedades modernas. São Paulo: Companhia das Letras, 1983.

MACKENZIE, Mairi. Ismos: para entender a moda. Tradução de Christiano Sensi. São Paulo: Globo, 2010.

NERY, Marie Louise. A evolução da indumentária: subsídios para a criação de figurino. Rio de Janeiro: Senac Nacional, 2007.

PALOMINO, Erika. A moda. 3. ed. São Paulo: Publifolha, 2010.

SCHNEID, Frantieska Huszar. Alinhavos da memória: o vestido de noiva do século XX. In: COLÓQUIO DE MODA, 10., 2014, Porto Alegre. Anais... Porto Alegre, 2014.

WORSLEY, Harriet. O vestido de noiva. Tradução de Dafne Melo. São Paulo: Publifolha, 2010. 